\title{
Multilocular cystic nephroma treated with laparoscopic nephron-sparing surgery: A case report
}

\author{
Biao Dong, MD; ${ }^{*}$ Yuantao Wang, MD; ${ }^{*}$ Jianjian Zhang, MD; ${ }^{\dagger}$ Yaowen Fu, MD; Gang Wang, MD, PhD
}

Biao Dong and Yuantao Wang contributed equally to this work.

*Department of Urology, First Hospital of Jilin University, Jilin, China; 'Department of Hepatic Surgery, Renii Hospital, Shanghai Jiaotong University School of Medicine, Shanghai, China

Cite as: Can Urol Assoc J 2014;8(7-8):e545-7. http://dx.doi.org/10.5489/cuaj.2020

Published online August 11, 2014.

\section{Abstract}

Multilocular cystic nephroma is a relatively rare benign tumour of the kidney, which usually presents as a unilateral multicystic renal mass without solid elements. The lesions typically have a bimodal age, with peak incidence in male children under 24 months and another one in women over 40 old. We present an unusual case report of multilocular cystic nephroma in the right kidney in a 30-year-old male. Laparoscopic partial nephrectomy was performed. The pathologic examination confirmed a multilocular cystic nephroma in the right renal specimens. We present the image findings, pathological features, treatment alternatives and a review of the literature.

\section{Introduction}

Multilocular cystic nephroma (MCN) is an uncommon clinical entity characterized by a well-circumscribed encapsulated mass that contains numerous locules and septa. ${ }^{1,2}$ Various designations have been used to describe this kidney lesion, including solitary multilocular cyst, benign multilocular cyst, multilocular renal cyst, cystic nephroma and multicystic nephroma. ${ }^{3-5}$ Most patients are asymptomatic and tumours are usually discovered incidentally. We report a case of a MCN in the upper pole of the right kidney that was successfully managed by laparoscopic nephron-sparing surgery. We summarize the clinical, radiographic, surgical and pathologic findings.

\section{Case report}

A 30-year-old man was admitted to hospital for evaluation of a 2-year history of intermittent right-flank pain and gross hematuria. He denied other voiding complaints and did not have other significant urologic issues. His physical examination was unremarkable except for mild knocking pain in the right kidney area. Urinalysis revealed a moderate amount of red blood cells in the sediment. Urine cytology was negative for malignancy.

Abdominal ultrasonography demonstrated a well-demarcated, $6.5 \times 4.4-\mathrm{cm}$ complex cystic mass which occupied the upper pole of the right kidney. Computed tomography (CT) showed a $5.9 \times 4.0-\mathrm{cm}$, polycystic, relatively wellcircumscribed, and heterogeneous mass in the upper pole of the right kidney (Fig. 1, part A). CT findings also showed that the cyst contained calcifications, but no solid components. An enhanced CT scan showed a poorly enchancing, cystic lesion protruding into the renal sinus (Fig. 1, part B). Based on the clinical and radiological findings, laparoscopic nephron-sparing surgery was performed to remove the tumours.

During the operation, the patient was placed in the $45^{\circ}$ left lateral position and 3 trocar ports were established: one alongside the right rectus abdominis and $2 \mathrm{~cm}$ below the umbilicus; the second at the midpoint between umbilicus and xiphoid, alongside the right rectus abdominis; and the third at the junction of right anterior axillary line and umbilical horizontal line. The renal blood vessels and surrounding tissues were identified and divided. The collateral blood supply of the mass was blocked by Hem-o-lok clip and the right renal artery was clipped temporarily by the laparoscopic artery clamp. The mass was completely resected using the ultrasonic knife. The surgeon loosened the laparoscopic artery clamp after the section of right kidney was sutured; the complete warm ischemia time was 18 minutes.

Macroscopic examination of the $5 \times 4.5 \times 3.5-\mathrm{cm}$ nephrectomy specimen revealed a $4.5 \times 3 \times 2-\mathrm{cm}$ tumoral mass in the upper pole of right kidney. Cut-section revealed a multilocular cystic lesion composed of numerous noncommunicating, fluid-filled cysts in various sizes, separated by unremarkable thin or relatively thicker fibrous septa. 


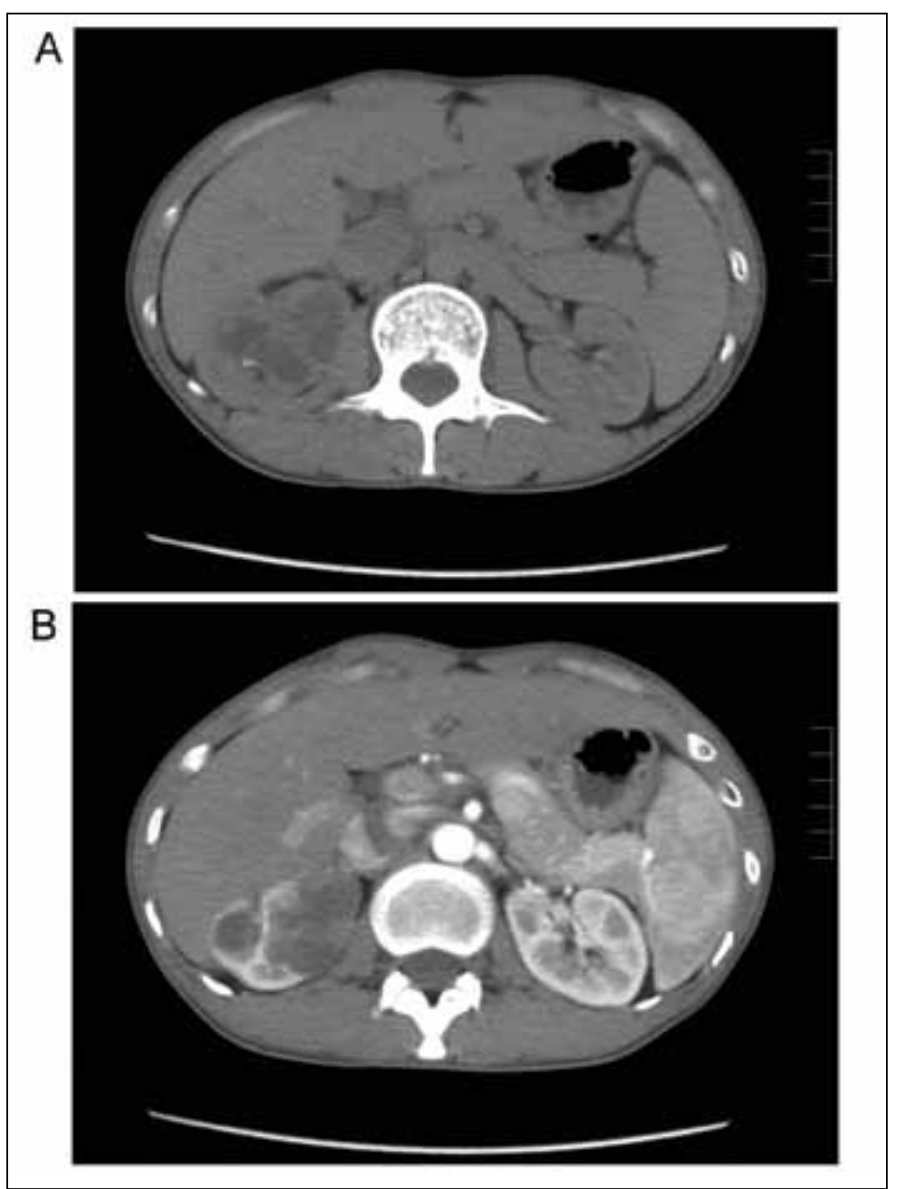

Fig. 1. A. Computed tomography scan showing a complex cystic mass in the upper pole of the right kidney. B: Contrast enhanced computerized tomography reveals a poorly enchancing, cystic lesion into the renal sinus.

Part of the capsule wall was hard, with calcification. On microscopic examination, the cysts were lined with variable epithelium, from flat to columnar. It also had hobnail epithelium in some areas and mature renal tubule in the fibre interval was also present (Fig. 2). The patient had an uneventful postoperative recovery and was discharged on postoperative day 10 . After the 2-year follow-up, the patient was well, with no recurrences.

\section{Discussion}

$\mathrm{MCN}$ is an uncommon, non-familial renal neoplasm that is usually benign. About 200 cases of this lesion have been described in the literature. The first case was reported in 1892 by Edmunds as "cystadenoma of the kidney." ${ }^{6}$ Most cases are asymptomatic and discovered incidentally during routine examination or radiological investigation, or presented with non-specific urinary tract symptoms in the adult and as an abdominal mass in the child. ${ }^{4}$ Our patient was a 30-year-old male, with symptoms of intermittent right-flank pain and hematuria.

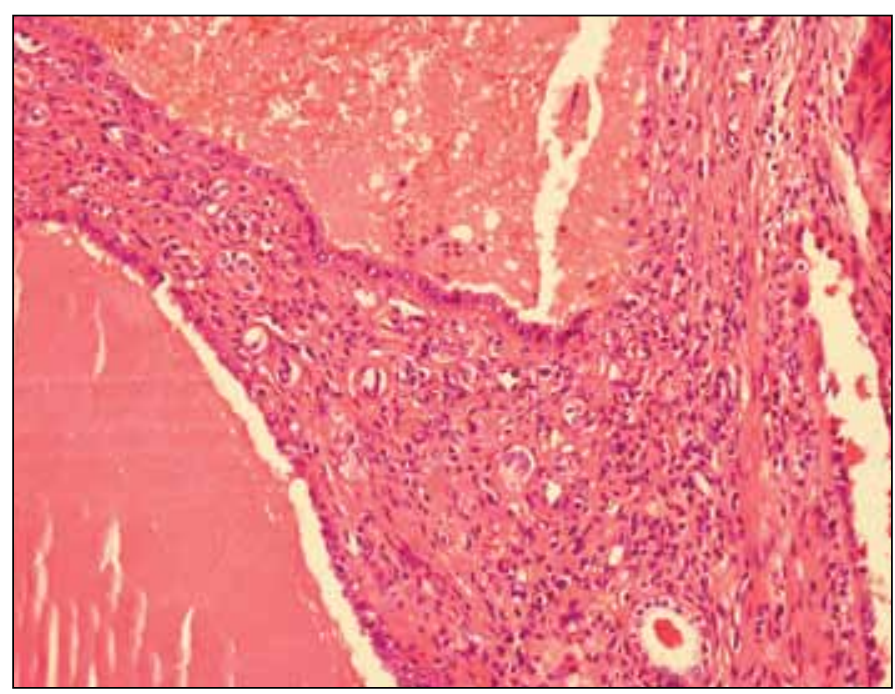

Fig. 2. High-power magnification shows hobnail and cuboidal epithelium lining the cystic lesion (hematoxylin and eosin staining; magnification, $\times 200$ ).

In 1956, Boggs and Kimmelstiel proposed the criteria for the diagnosis of a multilocular cyst. ${ }^{7}$ The criteria include: [a] a multilocular mass; [b] no communication between cysts; [c] cysts lined by epithelium; [d] no communication between cysts and pelvis; [e] remaining kidney essentially normal; and [f] no normal nephrons in the septa of cysts.

In 1989, Joshi and Beckwith made a modification of the criteria which specified that: [a] the tumour is composed entirely of cysts and their septa; [b] cystic nephroma is a discrete well-demarcated mass; [c] septa are the sole solid component and conform to the outlines of the cyst without expansive nodules; [d] cysts are lined by flattened, cuboidal, or hobnail epithelium; and [e] septa contain fibrous tissue, in which well-differentiated tubules may be present. ${ }^{8}$

The differential diagnosis of a cystic renal mass varies in adults and children, and may include polycystic kidney, nephroblastomas, Wilms' tumour, hydronephrotic kidney, mesoblastic nephroma and cystic renal cell carcinoma. However, neither preoperative imaging nor gross examination can reliably distinguish $\mathrm{MCN}$ from a malignant lesion of the kidney. Therefore, surgical intervention is required for both diagnosis and treatment. According to the literature, nephrectomy is an adequate treatment, with no need for chemotherapy and radiotherapy. ${ }^{9,10}$ In addition, the nephron-sparing technique is another appropriate choice for this lesion. ${ }^{11}$ Although published reports regard nephrectomy as the classic treatment modality for $\mathrm{MCN},{ }^{12,13}$ we suggest that nephron-sparing surgery may be an optimal treatment if the diagnosis of cystic nephroma is considered preoperatively and verified intraoperatively. Thus, a definitive diagnosis can usually be made from the pathology results when the operation is finished. Multilocularity, the absence of communication between the cyst and kidney tissue, the presence of locules with no communication between them, cysts filled 
with clear fluid, normal residual kidney and the absence of fully developed nephrons or part of the nephron in the septa of cysts are all characteristic features of multilocular cystic nephroma. In the present case, the preoperative diagnosis was multilocular cystic renal cell carcinomas and the postoperative pathology confirmed the diagnosis of $\mathrm{MCN}$.

\section{Conclusion}

We presented a rare case of a MCN as an unusual differential diagnosis of tumours. The combination of clinical, biochemical and radiological features may help in lesion characterization, but only histology can provide the definite diagnosis. Laparoscopic nephron-sparing surgery is one of the surgical treatment methods for MCN.

Competing interests: Biao Dong, Yuantao Wang, Jianjian Zhang, Yaowen Fu and Gang Wang all declare no competing financial or personal interests.

This paper has been peer-reviewed.

\section{References}

1. Bahilo Mateu MP, Budia Alba A, Boronat Tormo F, et al. Multilocular cystic nephroma. Actas Urol Esp 2010;34:921-3. http://dx.doi.org/10.1016/S2173-5786(10)70234-1

2. Subira RJ, Sanchez ZJM, Elizalde BA, et al. Muttilocular cystic nephroma. Report of three new cases. Arch Esp Urol 2009;62:62-6.

3. Powell T, Shackman R, Johnson HD. Multilocular cysts of the kidney. Br J Urol 1951;23:142-52. http:// dx.doi.org/10.1111/j.1464-410X.1951.tb02576.x

4. Castillo OA, Boyle ET, Kramer SA. Multilocular cysts of kidney. A study of 29 patients and review of literature. Urology 1991;37:156-62. http://dx.doi.org/10.1016/0090-4295(91)80214-R

5. Wood BP, Muurahainnen N, Anderson VM, et al. Multicystic nephroblastoma: Ultrasound diagnosis (with a pathologic-anatomic commentary). Pediatr Radiol 1982;12:43-7. http://dx.doi.org/10.1007/ BF01221712

6. Stamatiou K, Polizois K, Kollaitis $G$, et al. Cystic nephroma: A case report and review of the literature. Cases J 2008;1:267

7. Boggs LK, Kimmelstiel P. Benign multilocular cystic nephroma: Report of two cases of so-called multilocular cyst of the kidney. J Urol 1956;76:530-41.

8. Joshi W, Beckwith JB. Multilocular cyst of the kidney (cystic nephroma) and cystic, partially differentiated nephroblastoma. Terminology and criteria for diagnosis. Cancer 1989;64:466-79. http://dx.doi. org/10.1002/1097-0142(19890715)64:2<466::AID-CNCR2820640221>3.0.C0;2-V

9. Sharma S, Nagar R, Singh K, et al. Cystic nephroma: An unusual renal lesion. J Urol 2000;163:1860. http://dx.doi.org/10.1016/S0022-5347(05)67562-3

10. Bastian PJ, Kuhlmann R, Vogel J, et al. Local recurrence of a unilateral cystic nephroma. Int I Urol 2004;11:329-31. htrp://dx.doi.org/10.1111/j.1442-2042.2004.00787.x

11. Cheng EY, Cohn RA, Palmer LS, et al. A rare case of bilateral multilocular renal cysts. J Urol 1997;157:18612. http://dx.doi.org/10.1016/S0022-5347(01)64886-9

12. Füita K, Ueki T, Matsushima H. An atypical multilocular cystic nephroma presenting recurrent lumbago. Nihon Hinyokika Gakkai Zasshi 1993;84:1883-6.

13. Morga Egea JP, Fontana Compiano LO, Martinez F, et al. Multilocular cystic nephroma. A diagnostic and therapeutic challenge. Report of two cases. Arch Esp Urol 2000;57:431-4.

Correspondence: Dr. Gang Wang, Department of Urology, First Hospital of Jilin University, №.71 Xinmin Street, Changchun 130021, Jilin, China; wanggangidyy@163.com 